\title{
Following the growth of a rolling fatigue spalling for predictive maintenance
}

\author{
Omar Djebili $^{1, a}$, Fabrice Bolaers ${ }^{1}$, Ali Laggoun ${ }^{2}$ And Jean-Paul Dron $^{1}$ \\ 1 GRESPI, UFR, Sciences Exactes et Naturelles, Moulin de la Housse, BP 1039, 51687 Reims Cedex 2, France \\ 2 Departement de physique, Faculté des sciences UMBB, Boumerdes, Algerie
}

Received 12 December 2011, Accepted 12 December 2012

\begin{abstract}
The bearing is one of the most important components of rotating machines. Nevertheless, in normal conditions of use, it is subject to fatigue which creates a defect called a rolling fatigue spalling. In this work, we present a follow-up of the thrust bearing fatigue on a test bench. Vibration analysis is a method used to characterize the defect. In order to obtain the fatigue curve more adjusted, we have studied the vibration level according to statistical indicators: the Root Mean Square value (RMS value), which is one of the best indicators to show the evolution of the bearing degradation. The approach follows the working of the bearing until the degradation with an on line acquisition of vibration statements in form of time signals. With the signal treatment, we obtain the values of the vibration amplitudes which characterize the vibration state of the bearing. Consequently, these values allow us to plot the fatigue curves. During our experimental work, this operation is applied for a batch of thrust bearings for which we have obtained similar fatigue curves where the evolution trend follows a regression model from the detection of the onset of the first spall. The result of this work will contribute to predict the working residual time before failure.
\end{abstract}

Key words: Predictive maintenance / bearing / vibration analysis / spall / bearing fatigue

Résumé - Suivi de la croissance d'un écaillage de fatigue de roulement d'une butée à billes dans le cadre d'une maintenance prédictive. Le roulement est l'un des composants les plus importants des machines tournantes. Néanmoins, dans des conditions normales d'utilisation, il est soumis à la fatigue et subit un défaut d'écaillage de fatigue de roulement. Dans ce travail, nous présentons un suivi de la fatigue d'un roulement de butée sur un banc d'essai. L'analyse vibratoire est une méthode utilisée pour caractériser le défaut. Afin d'obtenir la courbe de fatigue plus ajustée, nous avons étudié le niveau vibratoire selon les indicateurs statistiques tel que la valeur RMS (Root Mean Square) qui est l'un des meilleurs indicateurs pour montrer l'évolution de la dégradation du roulement. L'approche suit le fonctionnement du roulement de butée jusqu'à la dégradation avec une acquisition en ligne des états vibratoires sous forme de signaux temporels. À l'aide du traitement de signal, on obtient les valeurs des amplitudes vibratoires qui caractérisent l'état vibratoire du roulement. Par conséquent, ces valeurs nous permettent de tracer les courbes de fatigue. Au cours de notre travail expérimental, cette opération est appliquée à un lot de butées à billes pour lesquelles nous avons obtenu des courbes semblables où la tendance de l'évolution suit un modèle de régression à partir de la détection de l'apparition de la première écaille. Le résultat de ce travail contribuera à prédire la durée de vie résiduelle avant la panne.

Mots clés : Maintenance prédictive / roulement / analyse vibratoire / écaillage / fatigue de roulement

\section{Introduction}

As a consequence of the extensive use and importance of bearings, bearing failures account for a large percentage of breakdowns in rotating machines. Such bearing failure can be catastrophic. From the day the rolling element bearings leave the factory, events take place that

${ }^{\mathrm{a}}$ Corresponding author: omar_djebili@yahoo.com reduce the designed running time to as low as tens of hours. There are several reasons that a bearing fails, such as improper storage, improper installation, poor lubrication, harsh operating environment, overload, over-speed etc. Even under normal operating conditions, a bearing will eventually fail due to fatigue. Complete elimination of bearing failure is not possible in practice.

Some defects (gear and bearing spallings) induce periodic impulse forces on the rotating machines that can 
excite the natural modes of the structure and of the sensor. Much research has been made concerning the detection and localization of a failure by vibration analysis. This technique is based on the study of a vibration signal from an accelerometer with two main types of indicators, time indicators [1] (RMS, kurtosis, crest factor) whose values are tied to a physical quantity derived from the power and from the peak amplitude of the vibration signal [2-4]; frequency indicators [5] (power spectrum, spectrum envelope, spectrum PBC, cepstrum...) which allow to locate the failed component of the machine. This work focuses on the follow-up of the failure. The objectives are firstly to determine the most relevant vibration indicator for providing information on the severity of a bearing spalling defect and then to estimate the parameters of a damage law associated with the degradation development.

\section{Degradation of bearings}

The degradation mechanism manifests in two levels of rolling fatigue degradation in the lubricated Hertz contacts [6]:

- micro chipping, which is characterized by the formation of micro cracks initiated in the subsurface material or on the damage surface, a damage which appears after a short incubation period even for a low normal load and which can lead to the ruin of the mechanism,

- spalling, is a damage which is characterized by the propagation of a fatigue crack in the Hertz area to the surface (spalling began in sub-layer) or from the surface to the under layer (chipping began at the surface). Spalling usually appears after a large number of cycles for normal loads.

According to physical metallurgy [7], the birth of the crack is linked to the presence of a stress concentration and to the emission of dislocations until a critical concentration. As far as the crack propagation is concerned, it results the emission of dislocations at the crack tip according to the applied stress field. Deep spalling initiated in the under-layer is the most common failure mode in bearings subjected to contact fatigue in elastohydrodynamic lubrication conditions and in bearings without sliding [8].

\section{Prediction models}

As part of predictive maintenance of bearings, it is not only important to detect a fault but also to follow its evolution over time in order to predict the residual life of the concerned component. The estimate of the residual life requires the knowledge and the formulation of a damage law that characterizes the growth of the spalling over time. The evolution of the spalling can be determined using global vibratory indicators which are statistical quantities calculated from the measurement of vibration signals. The follow up of the damage can be tackled in two ways. The first approach concerns the life prediction thanks to models based on the phenomena of initiation and crack propagation such as the Paris models $[4,5]$.
Li et al. $[9,10]$ found that the connection between the growth rate of the defect size and the characteristic of the material are based on the Paris model. This law can still be written as a power law that characterizes the level of a bearing damage under a given load. Physical approaches have also been developed to estimate the residual life of the bearings. They are based on the use of endurance curves that give the number of cycles to failure according to the applied stress and on the application of an accumulation law (most often, the Miner model) which allows to lead to the determination of life [11]. J. Qiu has used this model to predict the life of bearings [12]. The second approach concerns the state of functioning of the bearings and the diagnosis of the defects by the application of different methods such as the fuzzy logic [13] and neural networks [14-16]. The fuzzy logic is a decision method in an uncertain environment which consists in considering a variable which can only have two values or two sets (true or false) applied to the operation state of the bearings. These two sets become healthy or faulty. The method of the neural networks is used for the pattern recognition and allows to consider any system as a black box whose parameters are obtained from measurements (vibration signals), without a priori knowledge on the laws of the concerned process, by the learning phase. The output parameters are the diameter of the defect and its location is on a ring or on another one. Like most of the degradation models of bearings based on a mathematical power function (1), many experimental studies have led to the fatigue curves of a material, they generally follow a trend with a non-linear law [12] (Damage Curve Approach) $[9,17]$ (changes in the size of defect in time).

$$
D(t)=\alpha t^{\beta}
$$

where $D(t)$ is size spalling in $\mathrm{mm}^{2}, t$ is time in seconds, $\alpha$ and $\beta$ are two specific parameters.

Among the global indicators that can be used in vibration monitoring of the bearing degradation, we distinguish:

- the crest factor;

- the kurtosis;

- the crest value;

- the Root Mean Square value (RMS value).

The choice of the indicator fell on the RMS value whose expression of the effective value is given by (2)

$$
V_{\mathrm{RMS}}=\sqrt{\frac{1}{N} \sum_{i=1}^{N} x^{2}(n)}
$$

where $N$ is the number of samples taken from the signal and $x(n)$ the discrete time signal.

This choice is justified by the linear correlation [9] between the spalling size (surface) and the indicator value which is given in (3).

$$
V_{\mathrm{RMS}}=A D+B
$$

where $V_{\text {RMS }}$ is the RMS value, $D$ is the defect size in $\mathrm{mm}^{2}, A$ and $B$ are two coefficients. 


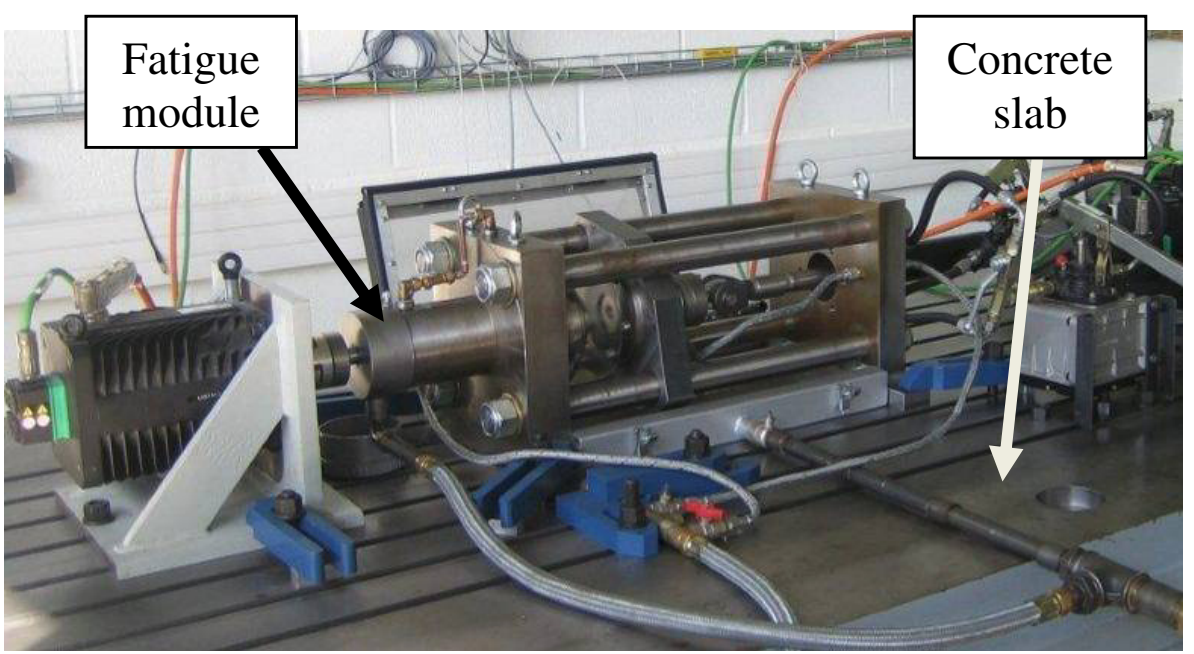

Fig. 1. Vibration test bench composed of the fatigue module and concrete slab.

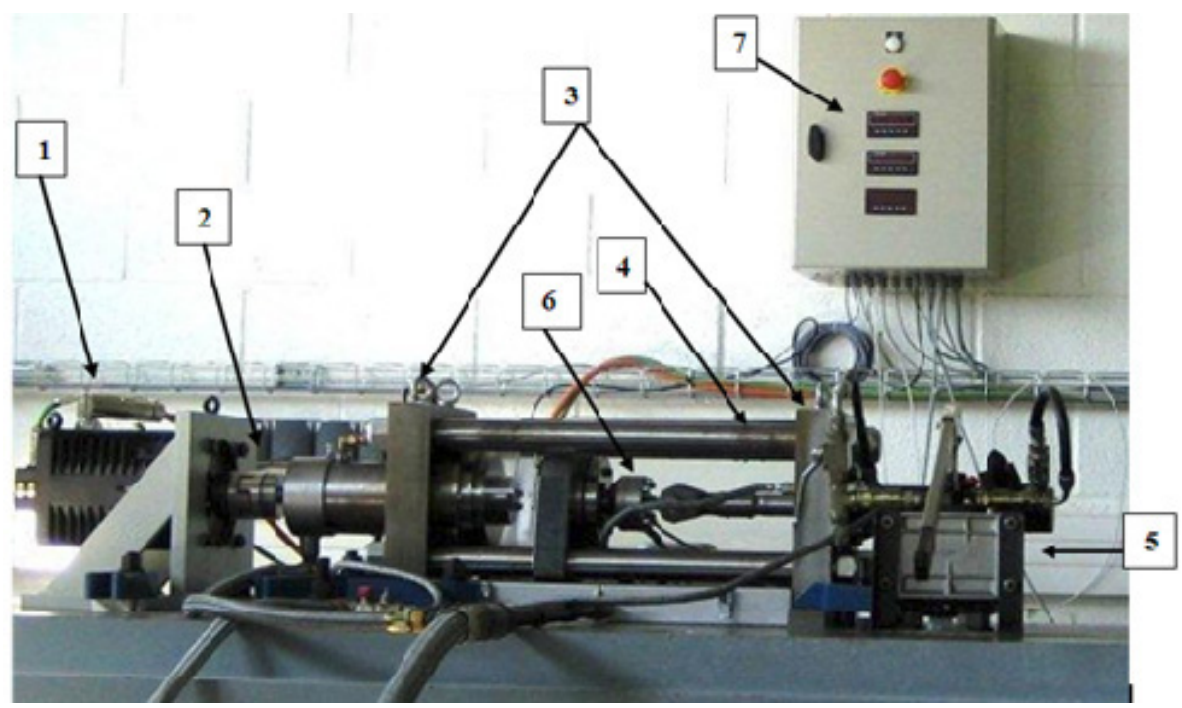

Fig. 2. Fatigue module of a thrust bearing.

The aim of our work is to experimentally demonstrate the correlation between the size of the defect and the RMS value and to show the good adaptation of the mathematical model in the prediction of the evolution of this defect size from the RMS value measurement of a vibration signal. This study is made on a test module dedicated to rolling fatigue. It consists in introducing a fatigue spall in a natural way by rolling fatigue. The test bench enables tracking the evolution of the spall in terms of its size and the vibration level, while controlling the operating conditions: load, rotation speed, lubrication, and temperature.

\section{Testing and validation}

\subsection{Test module of rolling fatigue}

The experimentation and the validation of the models previously defined were conducted on a rolling fatigue test bench set on a concrete seismic slab to filter out medium and high frequencies outside the system.

The fatigue module (Fig. 2) allows introduction of spalling defects in a natural way while controlling the parameters of load, rotation speed and lubrication to ensure the optimal operation of the bearing.

This fatigue module consists in three main parts: (i) base which is made of two plates (3) linked with four uprights (4); (ii) the operation part, including the main shaft (2) which goes through a plate to allow positioning of the thrust bearing to be tested on one of its ends, and the electric engine (1) which rotates the shaft by means of a coupling, (iii) the load device support, including the cylinder (5) which loads the press (6) to transmit the axial load on the thrust bearing by means of a rod, the intensity of the load is indicated by a display (7).

The bearings set on this module are thrust ball bearings (Fig. 3) whose technical characteristics are presented in Table 1. 
Table 1. Technical characteristics of the thrust ball bearing FAG 51207.

\begin{tabular}{cccccc}
\hline $\begin{array}{c}\text { Inner ring 1 } \\
\text { diameter }(\mathrm{mm})\end{array}$ & $\begin{array}{c}\text { Inner ring 2 } \\
\text { diameter }(\mathrm{mm})\end{array}$ & $\begin{array}{c}\text { Outer diameter } \\
(\mathrm{mm})\end{array}$ & $\begin{array}{c}\text { Number of } \\
\text { balls }\end{array}$ & $\begin{array}{c}\text { Ball diameter } \\
(\mathrm{mm})\end{array}$ & $\begin{array}{c}\text { Basic dynamic load } \\
\text { rating }(\mathrm{daN})\end{array}$ \\
\hline 35 & 37 & 62 & 12 & 9.52 & 3500 \\
\hline
\end{tabular}

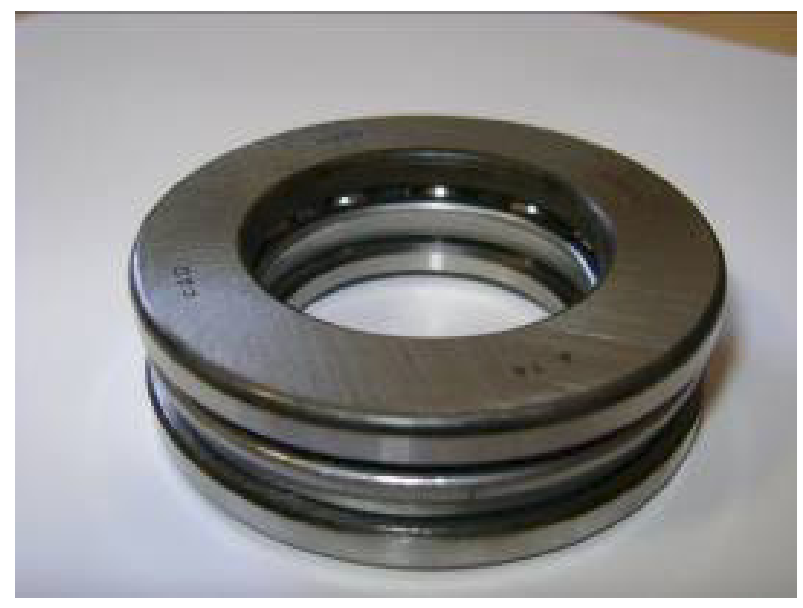

Fig. 3. Thrust ball bearing.

Regarding the details of the thrust ball bearing, it is of type FAG51207 CZECH/ATK under the action of the normal load $\mathrm{N}$, the resulted contact in the thrust ball bearing is between a sphere (ball of radius $\mathrm{R} 1$ ) and a ring of bearing (hollow raceway of radius $\mathrm{R} 2$ ), the contact surface is ellipse with semi-axes $a$ and $b$. The elasticity modulus of the material is

$$
E=210000 \text { N.mm }{ }^{-2} \text {. }
$$

The major advantage of this fatigue module mostly lies in the possibility to measure at any time the actual size of a spalling and to associate a vibration signal to this size.

\subsection{Spalling size and vibration indicator correlation}

It is to experimentally verify the assumption made by [9] which shows that the RMS acceleration value of the vibration signal can be associated with the size (surface) of a spalling. The tests were made on four thrust bearings. Two accelerometer sensors were placed (Fig. 4) close to the rolling elements. These ones are connected to an installation mainly consisting in an acquisition chain and the signals are instantly and continuously processed. The defects are naturally introduced on each thrust bearing by rolling fatigue thanks to a constant axial load of 3000 daN which results in Hertz pressure of $3.3 \mathrm{Gpa}$ and a constant rotation speed of $1800 \mathrm{rpm}$.

During the tests, the temperatures of the important points of the bench such as the landing of the main shaft of the machine, the lubricating oil (Castrol Magnaglide D68 with the viscosity of 50 cst at the temperature of $45^{\circ}$ ), the surrounding air, are continuously monitored on a synoptic board. A variation of a parameter is automatically detected. The temperature of the test bench stabilizes at a value of 60 to $64{ }^{\circ} \mathrm{C}$. The emergence of spalling

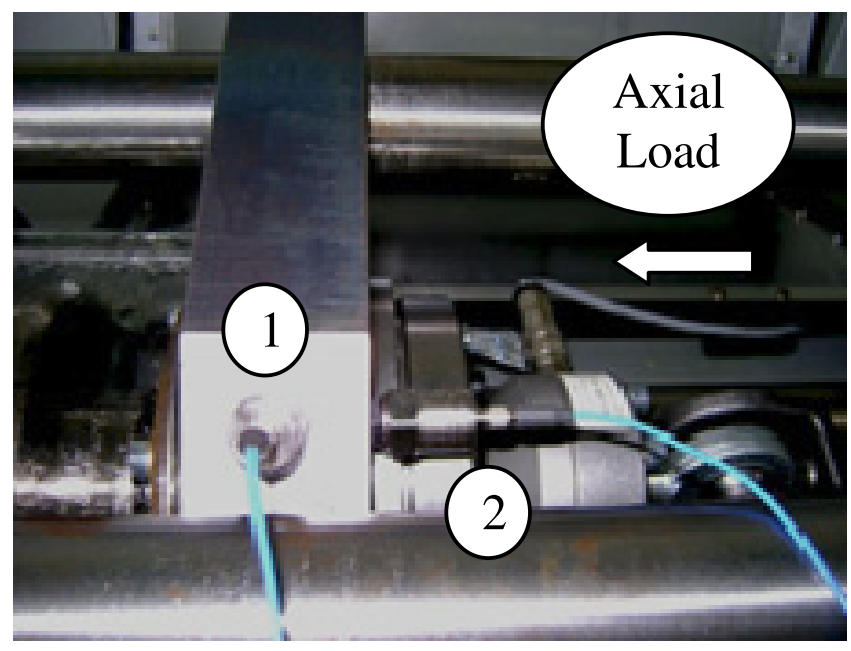

Fig. 4. Location of the sensors: sensor 1 (radial) and sensor 2 (axial).

Table 2. Summary of the fatigue tests on thrust bearings.

\begin{tabular}{ccccc}
\hline No. & Spalling ring & $\begin{array}{c}\text { Spalling } \\
\text { size }\left(\mathrm{mm}^{2}\right)\end{array}$ & $\begin{array}{c}\text { Functioning } \\
\text { time }\end{array}$ & $\begin{array}{c}\text { Spalling } \\
\text { time }\end{array}$ \\
\hline 1 & mobile & 80.14 & $67 \mathrm{~h} 20$ & $4 \mathrm{~h}$ \\
2 & mobile & 85.18 & $22 \mathrm{~h} 30$ & $4 \mathrm{~h}$ \\
3 & mobile & 98.55 & $24 \mathrm{~h}$ & $4 \mathrm{~h}$ \\
4 & mobile & 85.88 & $26 \mathrm{~h} 50$ & $3 \mathrm{~h} 30$ \\
\hline
\end{tabular}

defects is detected by using statistical indicators such as the kurtosis, the crest factor and the RMS value [18]. In order to correlate the size of the defect with the statistic vibration indicator, vibration measurements are performed in operation as a signal in the time domain. The conversion from time domain to frequency domain is done with a Fast Fourier Transformation (FFT). Then the vibration spectrum is filtered to make it clearer and precise. The spalling of the thrust bearing appears with a filtering in a high frequency band [19]. The thrust bearing is then removed in order to measure the surface of the spalling with a LEICA software which corrects the curve of the race and thanks to a microscope with a camera linked to a computer (Fig. 5).

The vibration measurement is read directly by the accelerometers and translated into a time signal by the acquisition card, and then this signal is converted into frequency signal using the fast Fourier transform and filtered in a band of high frequency to see more clearly the evolution of bearing failure (Fig. 5).

It is then possible to plot the evolution of the RMS acceleration value according to the surface of the spalling and to establish the linear correlation between these two measurements (Eq. (3)), (Fig. 6). 


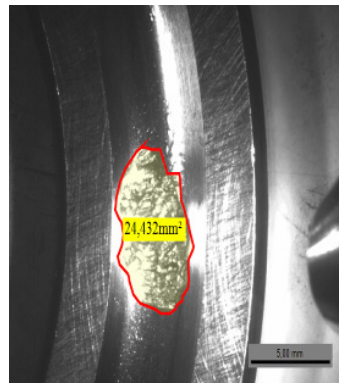

$\mathrm{D}=24.43 \mathrm{~mm}^{2}$
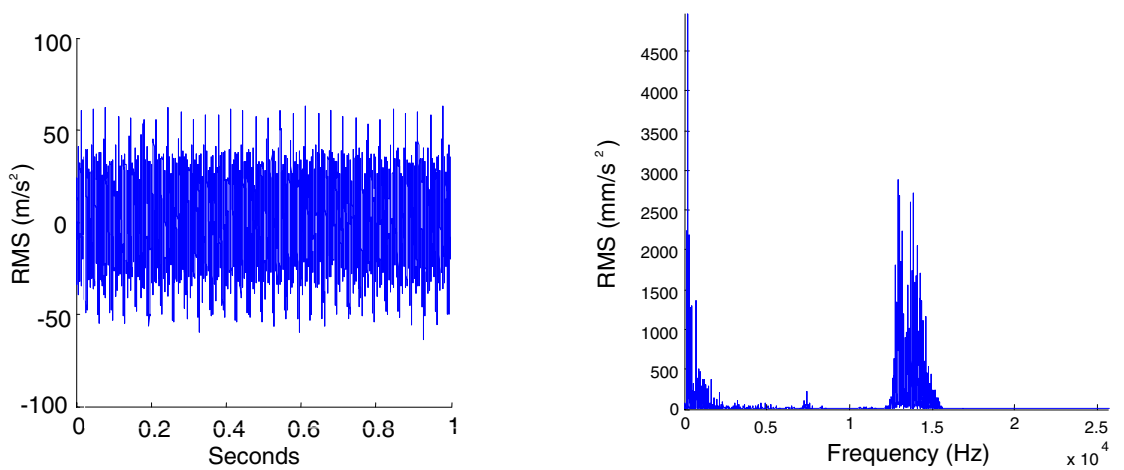

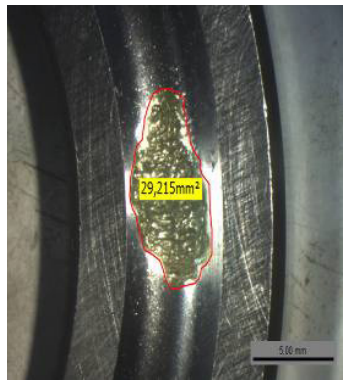

$\mathrm{D}=29.21 \mathrm{~mm}^{2}$
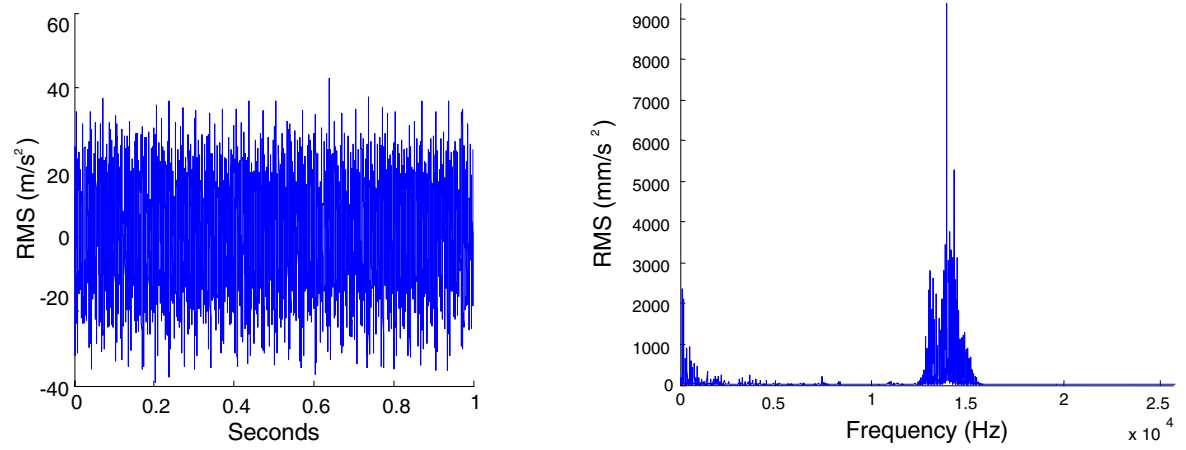

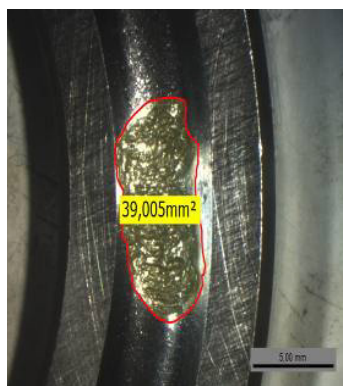

$\mathrm{D}=39 \mathrm{~mm}^{2}$
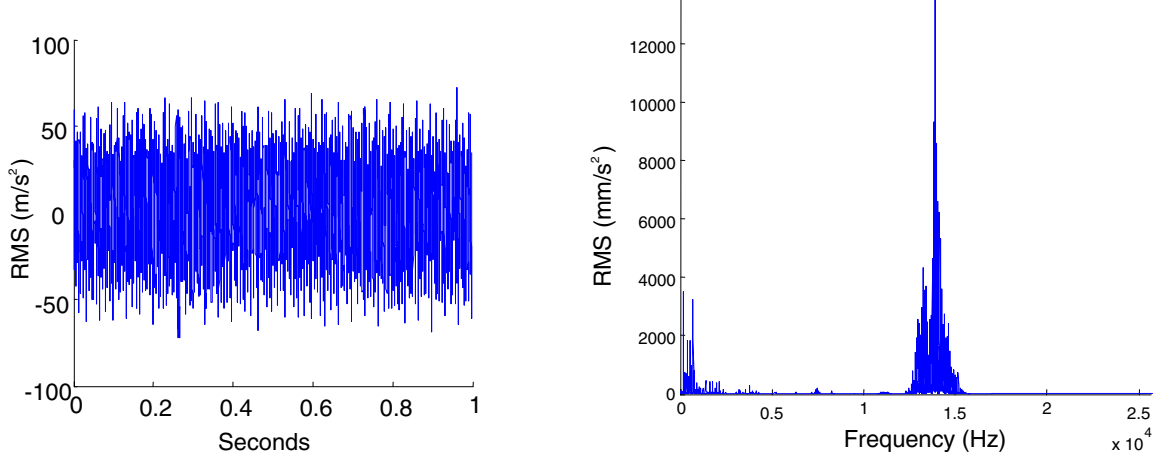

Fig. 5. Evolution of the indicator RMS according to the spalling size (frequency bandwidth: [13 to $15 \mathrm{kHz}$, signal time: $1 \mathrm{~s}$ and number of points: 51200 ).

The experimental results made on the four thrust bearings show a good correlation between the size of the spalling and the RMS value of the vibratory signal. For the last three thrust bearings, the correlation coefficient obtained is greater than 0.9 and it shows a good linearity between the size and the RMS value. In the case of the thrust bearing number 1 , the value of the correlation coefficient is equal to 0.7 , which also shows some instability between the size and the RMS value. This instability is due to the higher number of stops made on the fatigue module in order to measure the spalling size which does not allow to have a stabled temperature. Therefore, more stops produce less increase in temperature. It is the reason to have the difference between degradation trends of bearings (Fig. 7). As the bearing 1 was the purpose of the first test, we then thought to reduce the number of short stops of the test bed for other tests to better characterize the spalling of the thrust ball bearing. The other tests with a smaller number of stops have shown that the indicator values become more significant.

\subsection{Follow up of the evolution of a rolling spalling}

The application of the vibratory analysis as part of a conditional maintenance of rotating systems is initially 


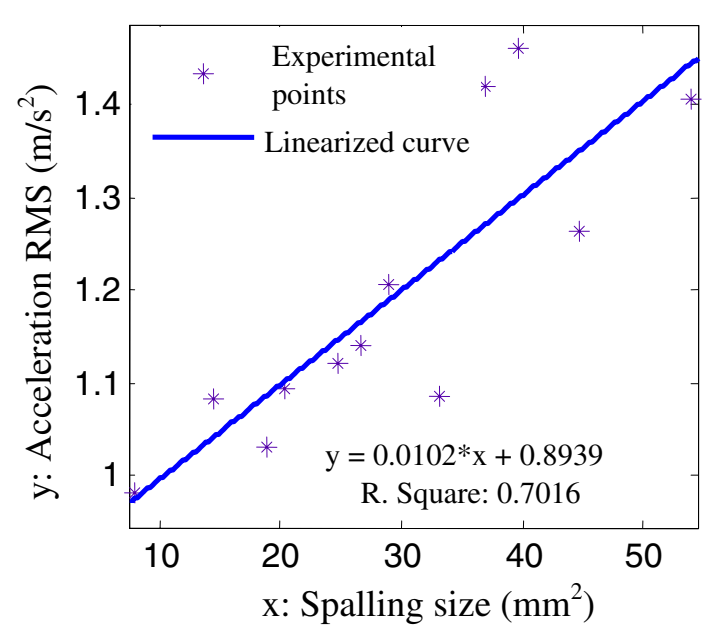

(a) bearing 1

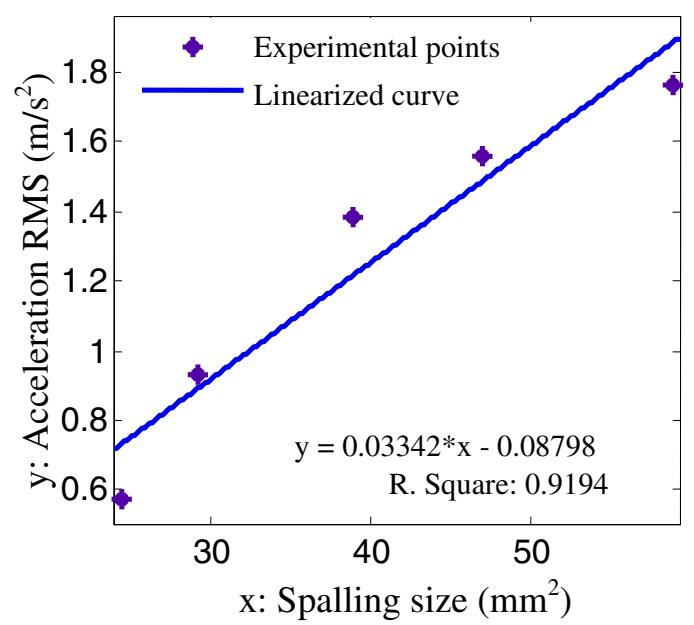

(c) bearing 3

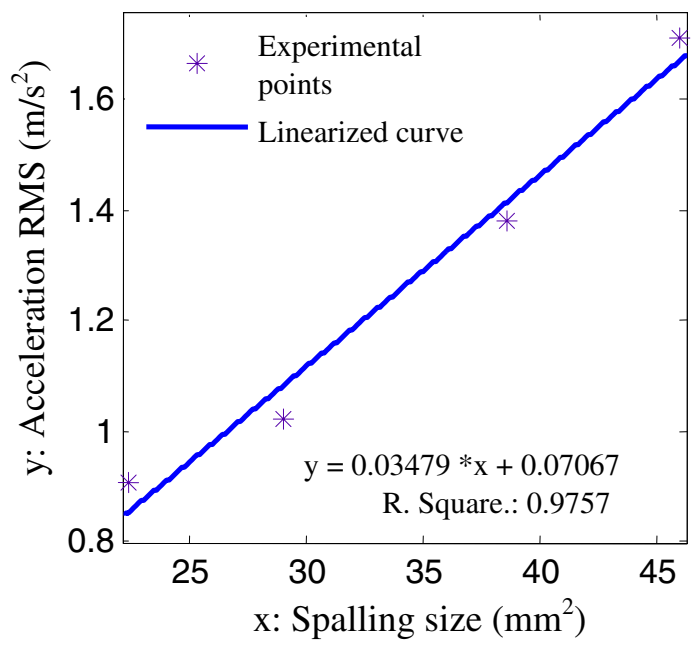

(b) bearing 2

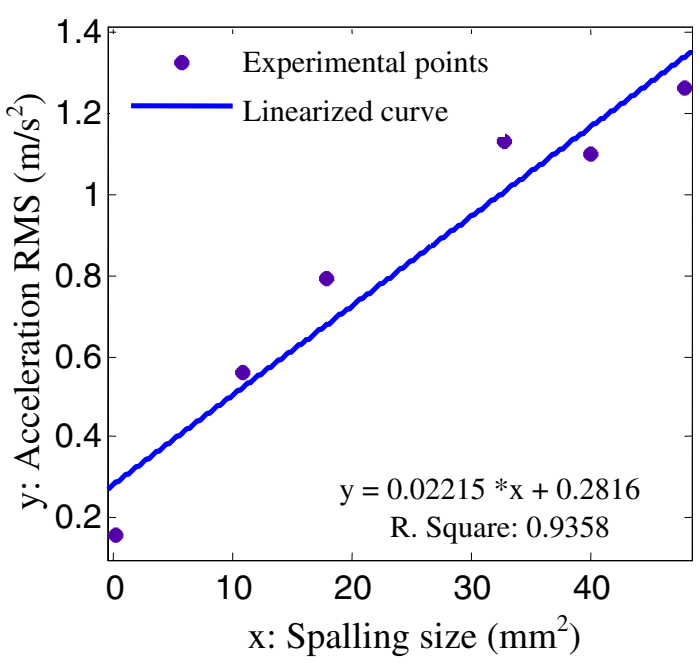

(d) bearing 4

Fig. 6. Evolution of the vibratory indicator according to the size of the spalling: (a) bearing 1, (b) bearing 2, (c) bearing 3 , (d) bearing 4 .

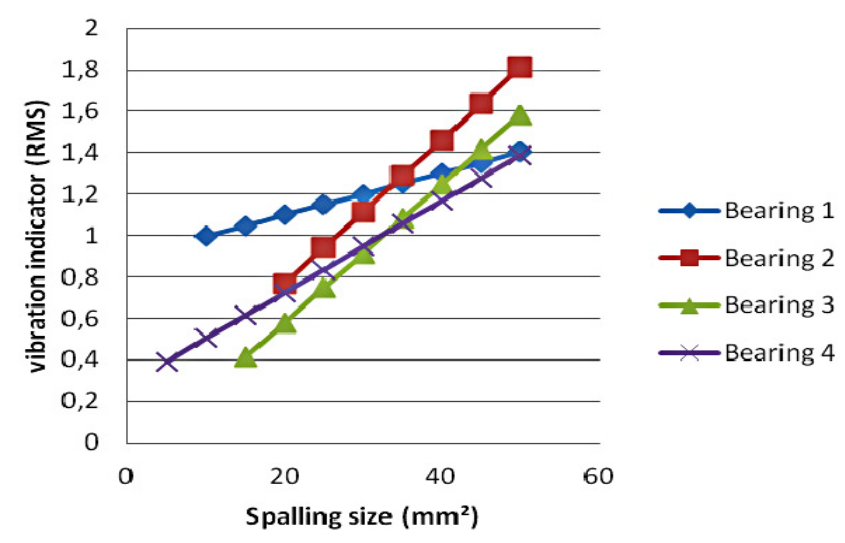

Fig. 7. Vibration indicator versus spalling size.

based on the development of a tendency curve allowing to monitor and to detect any deviations in its behavior.
When a failure occurs, it changes the vibration level and this tendency curve must qualify this change of state. This curve can be divided into two distinct parts: the first part characterizes the useful life of the thrust bearing and the second part characterizes the evolution of the damage (Fig. 8).

In our experimental work, all the successfully tested bearings have fatigue curves whose tendency is similar, like thrust bearings $1,2,3$ and 4 (Fig. 8). The curves of these bearings differ in comparison with the normal functioning duration of the thrusts before spalling. The spalling time is relatively short [20]. The spalling phase in the life of the thrust bearing is characterized by a sudden change of the vibratory response as it was shown by some researchers during their experimental work [9, 21, 22].

Our work will now be focused on the definition and the adaptation of a law which will allow to characterize 


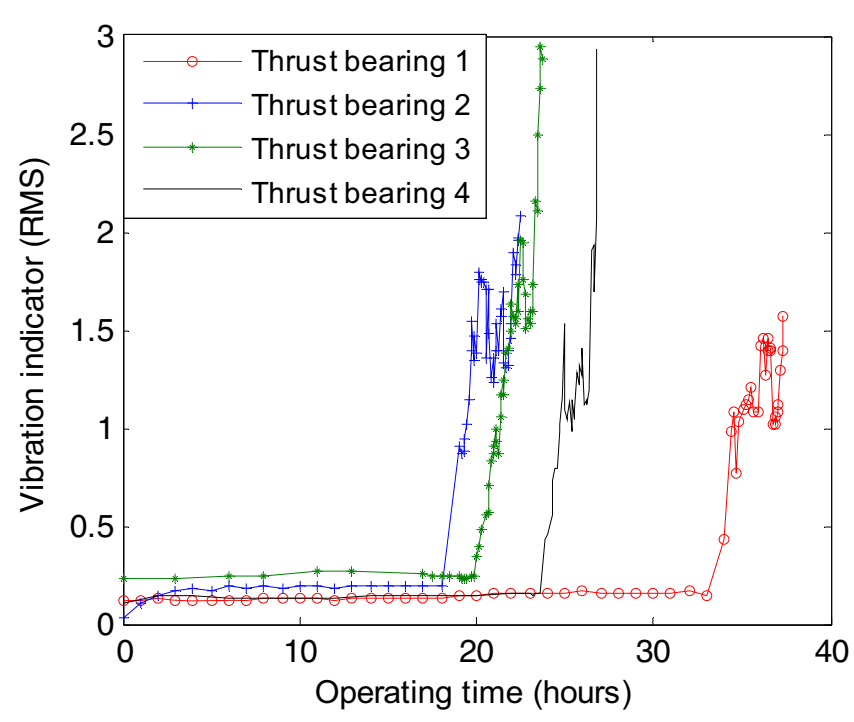

Fig. 8. Evolution curves of the vibratory level: axial sensor.

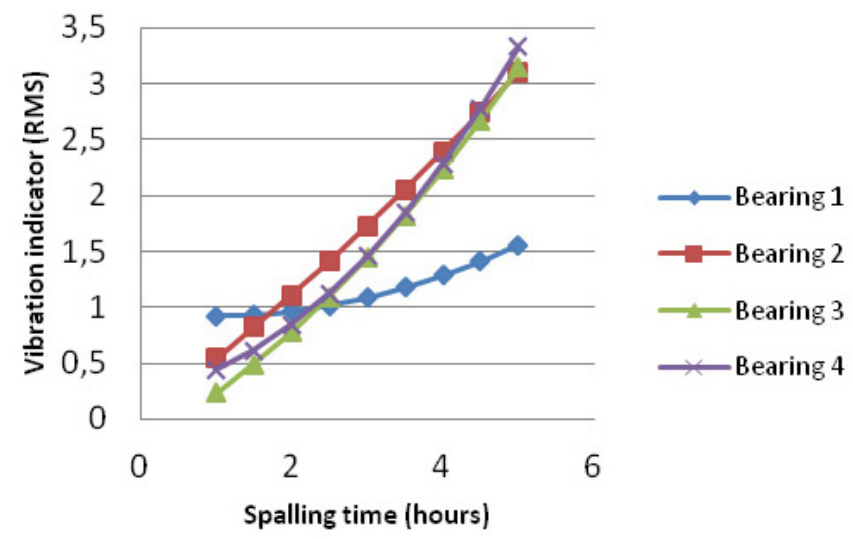

Fig. 9. Vibration indicator versus spalling time.

the second functioning phase of the thrust bearing (degradation phase) as it is shown in Figure 9.

\subsection{Definition of the growth law of the spalling}

The experimental tests of thrust bearing fatigues have allowed to obtain two types of results: the values of the amplitudes indicating the vibratory level of the degradation and the size of the defect representing the surface of the spalling.

The exploitation of these results allows us to mainly understand the tendency according to which the fatigue of a bearing evolves at first and secondly to find an approach to determine the residual life of the latter [23]. This work is focused on finding a physical law that changes the life of a thrust bearing under given operating conditions. As the time of normal functioning varies from a bearing to one another, the interest of the exploitation of the results is linked to the spalling phase. The tendency curves of the degradation of the bearings obtained during the fatigue tests for the period of spalling are represented in Figure 10.
Table 3. Values of the coefficients $a$ and $b$.

\begin{tabular}{cccc}
\hline No. & Functioning time & $a$ & $b$ \\
\hline 1 & $67 \mathrm{~h} 20$ & 1.25 & 2.46 \\
2 & $22 \mathrm{~h} 30$ & 13.47 & 1.148 \\
3 & $24 \mathrm{~h}$ & 9.678 & 1.412 \\
4 & $26 \mathrm{~h} 50$ & 7.163 & 1.822 \\
\hline
\end{tabular}

According to the tendency curves obtained for the thrust bearings on the tested spalling phase, the power law of type $a . x^{b}$ is the mathematical modeling that gives a better correlation to show the evolution of the defect. Through these tendency curves of the thrust bearings 1 , 2,3 and 4 , notice that the thrust bearing with the greatest life shows a spalling evolution curve which is growing faster. Indeed the thrust bearing 1 which shows an early spalling after $67 \mathrm{~h} 20$ has a growth rate of $b=2.46$, on the other hand, the thrust bearing 2 whose spalling begins after $22 \mathrm{~h} 30$ has a growth rate of $b=1.148$ (Fig. 11). Through the values of the coefficients $a$ and $b$ of the power law, we can notice that increasing the operating life of the thrust bearing results in the increase of the $b$ value and the decrease of the $a$ value (Tab. 3). We can also mention that the coefficient $b$ increases with the apparition of the spalling while the coefficient $a$ decreases at the same time. These coefficients characterize the nature of the tendency of the fatigue curve and the growth of the spalling.

We can notice that the fall of the vibration level is due to the presence of two balls at the same time in the spalling surface of the thrust bearing ring which means that the defect becomes more significant (Fig. 12). That's the reason why the vibration level values do not reflect the spalling size after this time.

Through this experimental work, it is found that the RMS value fall corresponds to a spalling size value of about $55 \mathrm{~mm}^{2}$ (the test must be stopped).

\section{Conclusion}

In this work, we have followed the operation of a thrust bearing operation under normal operating conditions (axial load, rotation speed of the shaft and coolant flow) until its spalling. This follow up is carried out as part of predictive maintenance of ball thrust bearings by vibratory analysis which consists in diagnosing a fatigue defect such as the spalling and in following it over time. The purpose of this follow up is to assess the growth rate of the spalling and to estimate a residual life of the bearing before its change. On a module dedicated to fatigue of thrust bearings and through several tests, we have obtained fatigue curves which join in a similar tendency. These trend curves have allowed, at first, to find the phases of evolution of the spall, by measuring the RMS value of the vibration according to the functioning time. Subsequently, we have been able to model the growth of the spalling by measuring its size according to the time. The treatment of the results obtained during these tests has allowed us to success in verifying the mathematical 

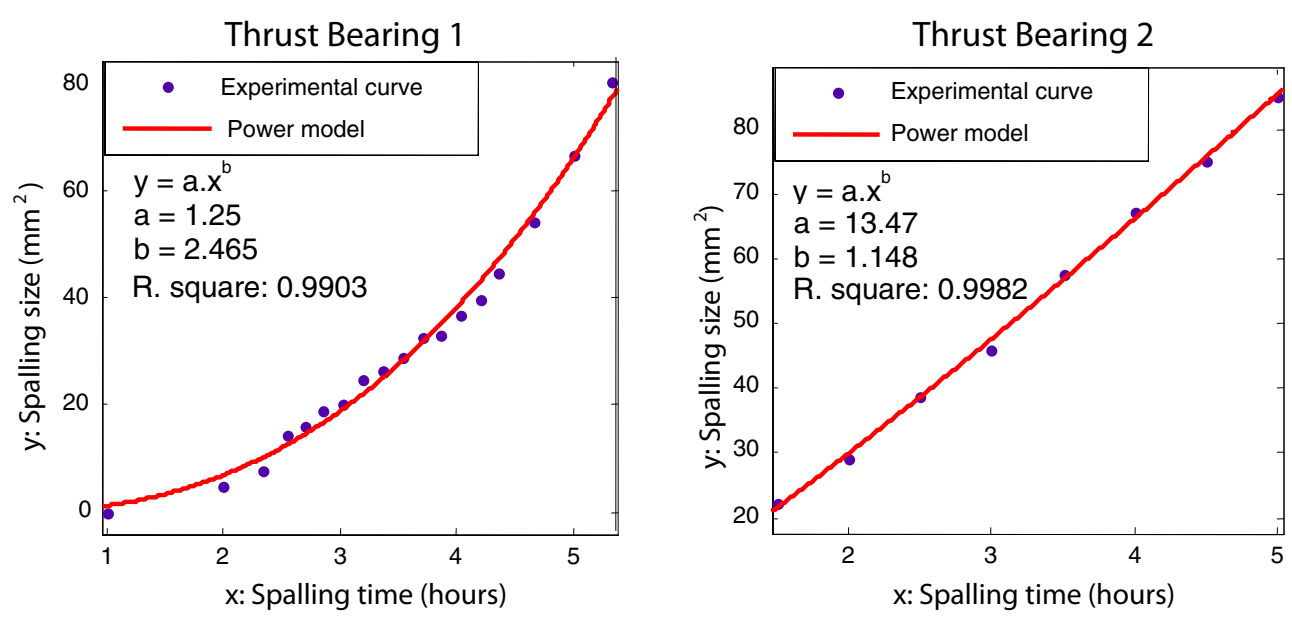

Thrust Bearing 3
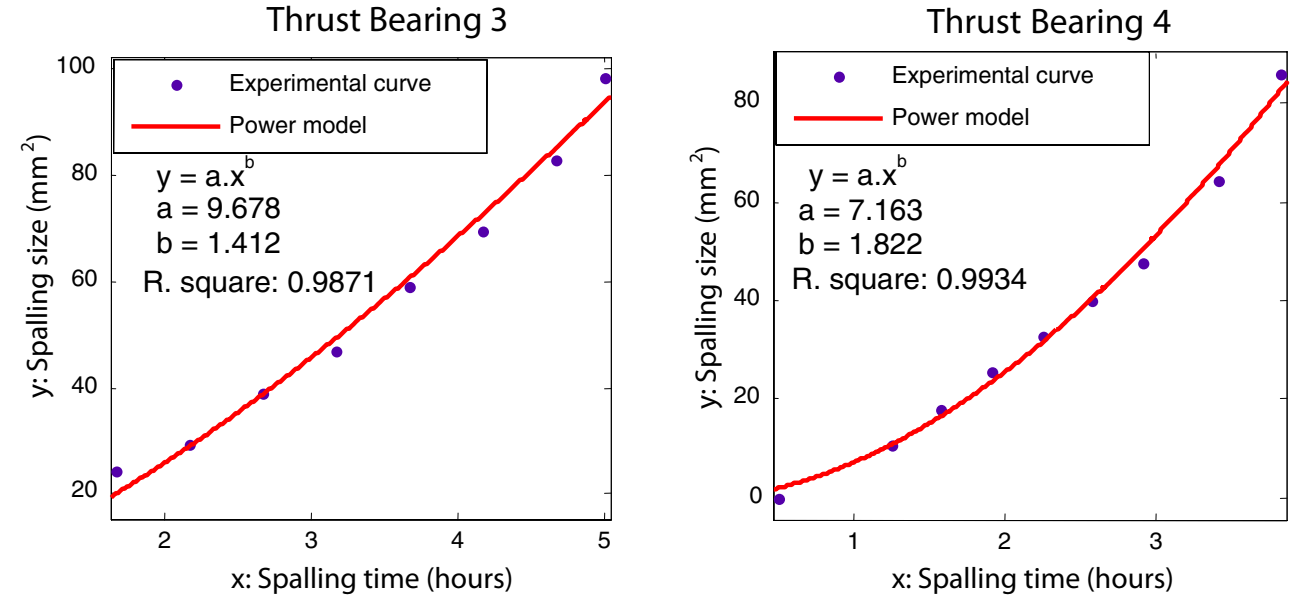

Fig. 10. Tendency curves of the spalling growth.

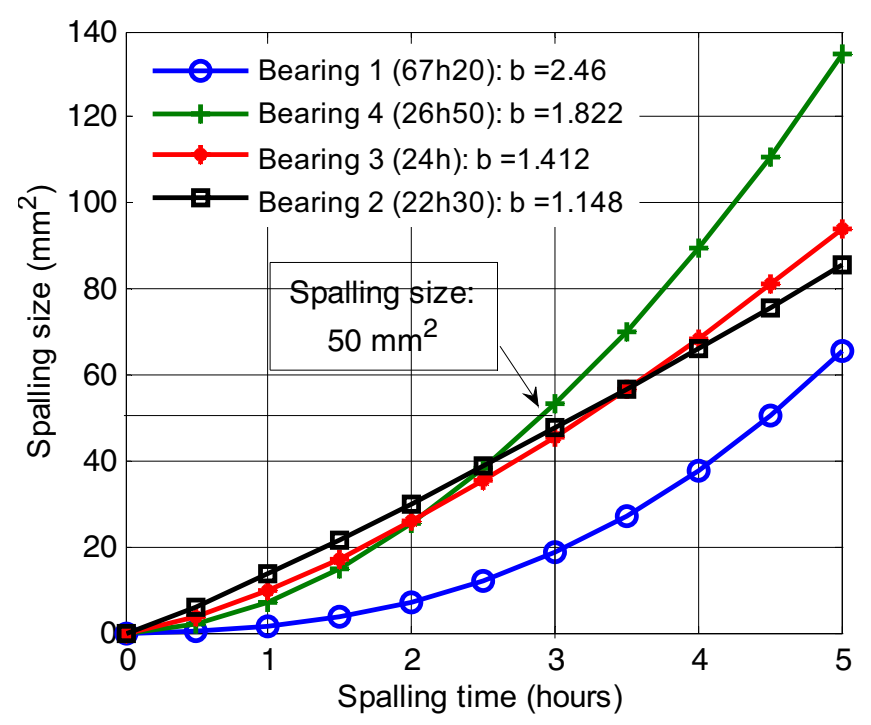

Fig. 11. Evolution of the value of the b coefficient of the law according to the live of the thrust bearing.

approach (power law) that we have chosen to describe the evolution of a thrust bearing degradation. We have

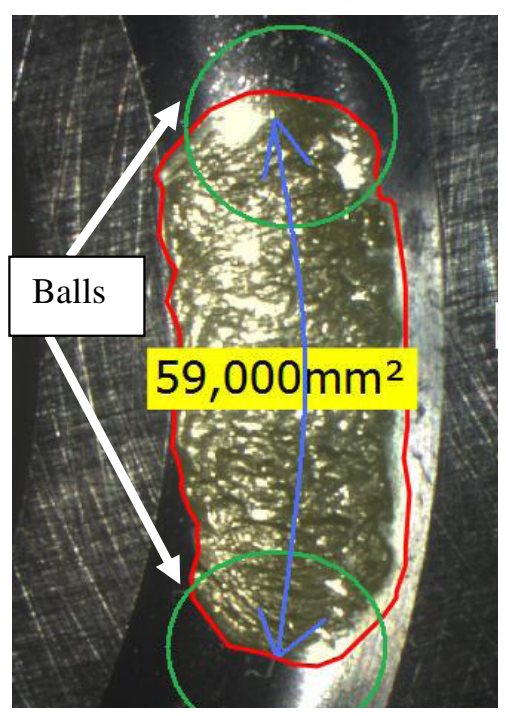

Fig. 12. Spalling size on the bearing ring.

finally shown that the growth of the spalling is faster when it appears later. This experimental work has allowed us to understand that the bearings may have different lifetimes with the same operating conditions. Nevertheless 
the spalling period (from the beginning to the propagation of the spalling) is relatively the same for a same operating mode. Therefore, the residual life of a bearing can be determined only during this spalling phase and this, when we set the threshold of maintenance (limit of the lifetime when a maintenance operation is required).

\section{References}

[1] R.J. Alfredson, J. Mathew, Frequency domain methods for monitoring the condition of rolling element bearings, Mech. Eng. Trans. Inst. Eng. Aust. 2 (1985) 102-107

[2] R.J. Alfredson, J. Mathew, Time domain methods for monitoring the condition of rolling element bearings, Mech. Eng. Trans, Inst. Eng. Aust. 2 (1985) 108-112

[3] P.F.J. Burgess, Antifriction bearing fault detection using envelope detection, Trans, Inst. Prof., New ZealandElect. Mech. Chem. Eng. Sec. 15 (1998) 77-82

[4] Y. Li, S. Billington, C. Zhang, Dynamic prognostic prediction of defect propagation on rolling element bearing, Lubrification Eng. 42 (1999) 385-392

[5] A. Palmgren, Ball and Roller Bearing Engineering, Philadelphia, PA: Burbank, 1959

[6] D. Nelias, Contribution à l'étude des roulements, Modélisation globale des roulements et avaries superficielles dans les contacts EHD pour des surfaces réelles ou indentées, Habilitation à diriger les recherches, Lyon : INSA de Lyon, 1999, $160 \mathrm{p}$.

[7] W. Cheng, H.S. Cheng, T. Mura, L.M. Keer, Micro mechanics modeling of crack initiation under contact fatigue, ASME J. Tribol. 116 (1994) 2-8

[8] D. Nelias, M.L. Dumont, F. Couhier, G. Dudragne, L. Flamand, Experimental and theorical investigation on rolling contact fatigue of 52100 and M50 steels under EHL or micro-EHL condition, ASME J. Tribol. 120 (1998) $184-190$

[9] Y. Li, S. Billigton, C. Zhang, T. Kurfess, S. Danyluk, S. Liang, Adaptive pronostics for rolling element bearing condition, Mech. Syst. Signal Proc. 13 (1999) 103-113

[10] Y. Li, T.R. Kurfess, S.Y. Liang, Stochastic prognostics for rolling element bearings, Mech. Syst. Signal Proc. 14 (2000) $747-762$
[11] J. Shiroishi, Y. Li, T. Kurfess, S. Danyluk, Bearing condition diagnostics via vibration and acoustic emission measurements, Mech. Syst. Signal Proc. 11 (1997) 693-705

[12] J. Qiu, B.B. Set, S.Y. Liang, C. Zhang, Damage mechanics approach for bearing lifetime prognostics, Mech. Syst. Signal Proc. 16 (2002) 817-829

[13] T.I. Liu, J.H. Singonhalli, Detection of roller bearing defects using expert system and fuzzy logic, Mech. Syst. Signal Proc. 10 (1996) 595-614

[14] I.E. Alguindigue, A. Loskiewicz-Buczak, R.E. Ubrig, Monitoring and diagnosis of rolling element bearings using artificial neural networks, IEEE Trans. Ind. Electron 40 (1993) 209-217

[15] Y. Shao, K. Nezu, Prognosis of remaining bearing life using neural networks, Proc. Inst. Mech. Eng., J. Syst. Control. Eng. 214 (2000) 217-230

[16] R. Huanga, L. Xia, X. Lib, C. Liuc, H. Qiud, J.L. Richard, Residual life predictions for ball bearings based on selforganizing map and back propagation neural network methods, Mech. Syst. Signal Proc. 21 (2007) 193-207

[17] A. Ray, S. Tangirala, Stochastic modeling of fatigue crack dynamics for on-line failure prognostics, IEEE Trans. Control Systems Technol. 4 (1996) 4

[18] P.D. McFadden, J.D. Smith, Vibration monitoring of rolling element bearings by the high frequency resonance technique, Rev. Tribol. Int. 17 (1984) 3-10

[19] R.B. Randall, J. Antoni, Rolling element bearing diagnostics, Mech. Sys. Signal Proc. (2011) 485-520

[20] T. Williams, X. Ribadeneira, Rolling element bearing diagnostics in run-to-failure lifetime testing, Mech. Syst. Signal Proc. 15 (2001) 979-993

[21] H. Qiu, J. Lee, J. Lin, Y. Gang, Robust performance degradation assessment methods for enhanced rolling element bearing prognostics, Advanced Engineering Informatics 17 (2003) 127-140

[22] N. Gebraeel, M. Lawley, Residual life predictions from vibration-based degradation signals: A neural network approach, IEEE Trans. Industrial Elect. 51 (2004)

[23] L. Rosado, N.H. Forster, K.L. Thomson, J.W. Cooke, Rolling contact fatigue life and spall propagation of AISI M50, M50NiL, and AISI 52100, Part I: Experimental Results, Tribol. Trans. 53 (2010) 29-41 